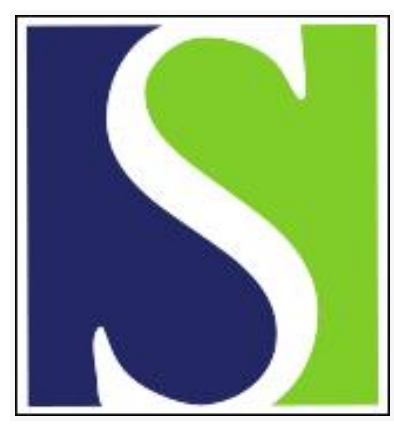

Scand J Work Environ Health 1998;24(4):308-311

https://doi.org/10.5271/sjweh.325

Issue date: Aug 1998

Experience with a vocabulary test for workers previously and still exposed to styrene

by Viaene $M$, Veulemans $H$, Masschelein $\mathrm{R}$

Key terms: hold test; neurobehavioral epidemiologic study; organic solvent

This article in PubMed: www.ncbi.nlm.nih.gov/pubmed/9754863

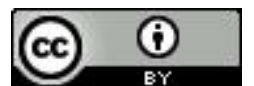




\title{
Experience with a vocabulary test for workers previously and still exposed to styrene
}

by Mine Viaene, MD, ${ }^{1}$ Hendrik Veulemans, PhD, ${ }^{1}$ Raphaël Masschelein, $M D^{1}$

\begin{abstract}
Viaene $M$, Veulemans $H$, Masschelein R. Experience with a vocabulary test for workers previously and still exposed to styrene. Scand J Work Environ Health 1998;24(4):308-311.

Objectives This study examined the possible influence of styrene exposure on the results of vocabulary tests because verbal ability is assumed to be relatively resistant to the toxic effects of organic solvents and short vocabulary tests are used as "hold tests" in many neurobehavioral epidemiologic studies,

Methods To evaluate the chronic neurotoxic effects of styrene, a vocabulary test was administered to a group of still-exposed workers ( $N=27$ ) and an earlier exposed group of workers $(\mathrm{N}=90)$. A self-administered questionnaire was filled out on life events, general health, educational level, and amount of education. The still-exposed group had a mean exposure duration of 4700 hours, and that for the formerly exposed group was 3610 hours.

Results The vocabulary score of the still-exposed group was significantly lower [12.5 (SD 2.9, range 6-18)] than that of their former colleagues [14.3 (SD 3.4, range 8-22)], even though they originally belonged to the same group and had done the same tasks. The exposure duration explained a significant part of the vocabulary results, resulting in decreasing vocabulary scores even when the influence of years of education and age was taken into account. Even after correction for the possible influence of having been laid off or staying at work, there remained a negative influence on the vocabulary score for the duration of styrene exposure.

Conclusions The use of short vocabulary tests as hold tests in cross-sectional studies of solvent-exposed workers may be limited as they seem to lack the essential toxicity-independent property.
\end{abstract}

Key terms hold test, neurobehavioral, organic solvents.

The intellectual capacity of test persons greatly influences the results of the many neurobehavioral tests used in epidemiologic studies on the effects of neurotoxic substances on healthy workers. The neuroperformance effects caused by occupational exposure to neurotoxins, such as solvents, pesticides or metals, are rather small under normal work conditions. To arrive at convincing conclusions about these neuroperformance deficits, it is very important that the exposed and reference workers be comparable regarding their premorbid intellectual level or that valid measurements of this capacity are used as a covariable in the statistical analysis (1). For this purpose, many authors in occupational neurotoxicology have tried to estimate intelligence with short vocabulary tests, whose results are presumed to be relatively resistant to the toxic effects and are, for this reason, often called "hold tests". Not using these tests was even regarded as evidence of poor study design by Lehrl et al (2). We noticed a difference in vocabulary test results in a group of workers previously exposed to styrene in comparison with colleagues who were still exposed to styrene. This finding was not expected because both groups had been doing the same jobs and belonged originally to the same group. Therefore, we examined the possible influence of prolonged styrene exposure.

\section{Subjects and methods}

We conducted cross-sectional exposure studies involving full-shift personal monitoring, biomonitoring, and peak measurements in a styrene polyester shipbuilding factory from 1983 to 1986 (3). During these studies, the presence of some neurotoxic complaints was noted. For economic reasons, the production stopped in 1989, and only a small number of workers remained at work $(\mathrm{N}=31)$. Workers were made redundant on the grounds of age (>50 years retired), and if they were not a "head of the family" (a person economically very important for other family members, eg, the combination of being married, having no working spouse and having children). No potential bias, according to verbal ability, seems to be 
involved by this dismissal procedure. Three years later, we retraced all the workers previously engaged in our first studies ( $\mathrm{N}=185)$ to investigate chronic irreversible neurotoxic effects (4). Nineteen persons $(10.3 \%)$ were lost for examination (deceased, abroad, no address), 31 (16.8\%) refused to participate, $17(9.2 \%)$ had to be excluded due to confounding factors (diabetes, craniocerebral trauma, alcoholism, depression), and $1(0.01 \%)$ computer file with the test results was unreadable. Finally, $117(63.4 \%)$ persons were included for testing, of which 27 came from the still-exposed group and 90 came from the formerly exposed group. The level and duration of exposure were well documented in this study. Due to detailed records on individual tasks, the total number of hours that every individual worker spent in exposed jobs could be calculated. The still-exposed group had been laminating for 4700 (SD 1870, range 530-7505) hours, while the formerly exposed group had been laminating for a shorter period of 3610 (SD 2000, range (165-8098) hours. In addition, daily direct reading measurements had been done with colorimetric tubes for the exposed jobs by the occupational hygienist. The reliability of these measurements was estimated by comparing them, where possible, with the environmental monitoring results of our exposure studies (3). The correlation between both sets of data was good (linear regression $\mathrm{r}^{2}=0.83, \mathrm{P}<0.01$ ). The median air exposure was calculated for every person. In the still-exposed group, the median exposure to styrene during lamination tasks was 147.6 (SD 14.1, range $124.0-173.2) \mathrm{mg} / \mathrm{m}^{3}$. This value was comparable with the exposure level of the formerly exposed group [156.6 (SD 19.0, range 98.8-188.8) $\left.\mathrm{mg} / \mathrm{m}^{3}\right]$. Although an efficient ventilation system kept exposure levels low, it must be noted that, in our exposure studies, $4 \%$ to $9 \%$ of the biomonitoring and personal monitoring measurements were above the permissible time-weighted average $\left(213 \mathrm{mg} / \mathrm{m}^{3}\right)$, and $4 \%$ of the peak exposure measure-

Table 1. Pearson correlation coefficient matrix of the vocabulary score and the covariates used in the multiple regression analysis. ( $F E G=$ formerly exposed group)

\begin{tabular}{|c|c|c|c|c|c|}
\hline & $\begin{array}{c}\text { Duration } \\
\text { of } \\
\text { exposure } \\
\text { (hours) }\end{array}$ & $\begin{array}{c}\text { Vocabulary } \\
\text { score } \\
(0-22)\end{array}$ & $\begin{array}{l}\text { Years of } \\
\text { education }\end{array}$ & $\begin{array}{c}\text { Age } \\
\text { (years) }\end{array}$ & FEG $(0 / 1)^{\mathrm{a}}$ \\
\hline $\begin{array}{l}\text { Duration of } \\
\text { exposure } \\
\text { (hours) }\end{array}$ & 1 & & & & \\
\hline $\begin{array}{l}\text { Vocabulary } \\
\text { score }(0-22)\end{array}$ & $\begin{array}{r}-0.25 \\
P<0.01\end{array}$ & 1 & & & \\
\hline $\begin{array}{l}\text { Years of } \\
\text { education }\end{array}$ & $\begin{array}{r}-0.12 \\
P=0.22\end{array}$ & $\begin{array}{r}0.19 \\
P=0.04\end{array}$ & 1 & & \\
\hline Age (years) & $\begin{array}{r}-0.10 \\
P=0.30\end{array}$ & $\begin{array}{r}-0.09 \\
P=0.36\end{array}$ & $\begin{array}{r}-0.31 \\
P<0.01\end{array}$ & 1 & \\
\hline FEG $(0 / 1)^{\mathrm{a}}$ & $\begin{array}{r}0.23 \\
P=0.01\end{array}$ & $\begin{array}{r}0.22 \\
P=0.01\end{array}$ & $\begin{array}{r}0.14 \\
P=0.14\end{array}$ & $\begin{array}{r}-0.04 \\
P=0.64\end{array}$ & 1 \\
\hline
\end{tabular}

a Belonging to the FEG or not. ments were above the short-term exposure limit $(426 \mathrm{mg}$ / $\left.\mathrm{m}^{3}\right)$.

To measure premorbid intelligence, a self-administered questionnaire was used to check for the schooling level (5 levels) and number of years of education. The level of education was distributed as follows: $22.2 \%$ and $12.2 \%$ had finished the lowest level, $22.2 \%$ and $17.8 \%$ had finished the second level, $40.7 \%$ and $48.9 \%$ had finished the third level, $14.8 \%$ and $16.7 \%$ had finished the 4 th level, and $0 \%$ and $4.4 \%$ had finished the highest lev$\mathrm{el}$ in the still-exposed group and the formerly exposed group, respectively. Of the workers who were not included in the study, 34\% had finished the lowest level, $26 \%$ the second level, $32 \%$ the third level, and $6 \%$ the 4 th level.

The mean length of education was 10.6 (SD 2.0, range $7-14$ ) years in the still-exposed group and 11.3 (SD 2.3, range 7-21) in the formerly exposed group. In addition, the Dutch version of the vocabulary test of the Neurobehavioral Examination System (NES) (5) was administered.

Multiple linear regression was performed with the vocabulary results as the outcome variable and the level or duration of exposure, years of education, and age as the covariates. For many years, all children have had to attend school until 18 years of age, and therefore years of education was less useful for the youngest workers. Therefore, an analysis of covariance with the level of education as the classification variable, vocabulary as the outcome variable, and age and level or duration of exposure as the covariates was also performed.

\section{Results}

The vocabulary score of the still-exposed group was significantly lower [12.5 (SD 2.9, range 6-18)] than that of their former colleagues [14.3 (SD 3.4, range 8-22)] (Students' t-test $\mathbf{P}=0.01$ ). In the multiple linear regression only the exposure duration explained a significant part of the vocabulary results (partial $r=-0.24, P=0.01$ ), resulting in decreasing vocabulary results. Age (partial $r=-0.07, P=0.47$ ) and years of education (partial $r=0.14$, $\mathrm{P}=0.13$ ) did not explain a significant part of the results in our study. The adjusted coefficient of multiple determination $\left(\mathrm{r}^{2}\right)$ of the model was $0.07(\mathrm{P}=0.01)$. The Pearson correlation coefficient matrix is given in table 1 .

In the analysis of covariance almost the same results were obtained; the schooling level (partial $\mathrm{r}=0.28$, $\mathrm{P}=0.06$ ) and the exposure duration (partial $\mathrm{r}=-0.24$, $\mathrm{P}<0.01$ ) explained a (borderline) significant part of the vocabulary results (adjusted $\mathrm{r}^{2}$ model $=0.10, \mathrm{P}<0.01$ ). The effect of age was not significant $(\mathrm{P}=0.83)$. No relation with the level of exposure was found (analysis of covariance and multiple linear regression, $\mathrm{P}>0.10$ ).

In addition, the vocabulary results were corrected for the influence of being formerly exposed or not $(0 ; 1)$, age, 


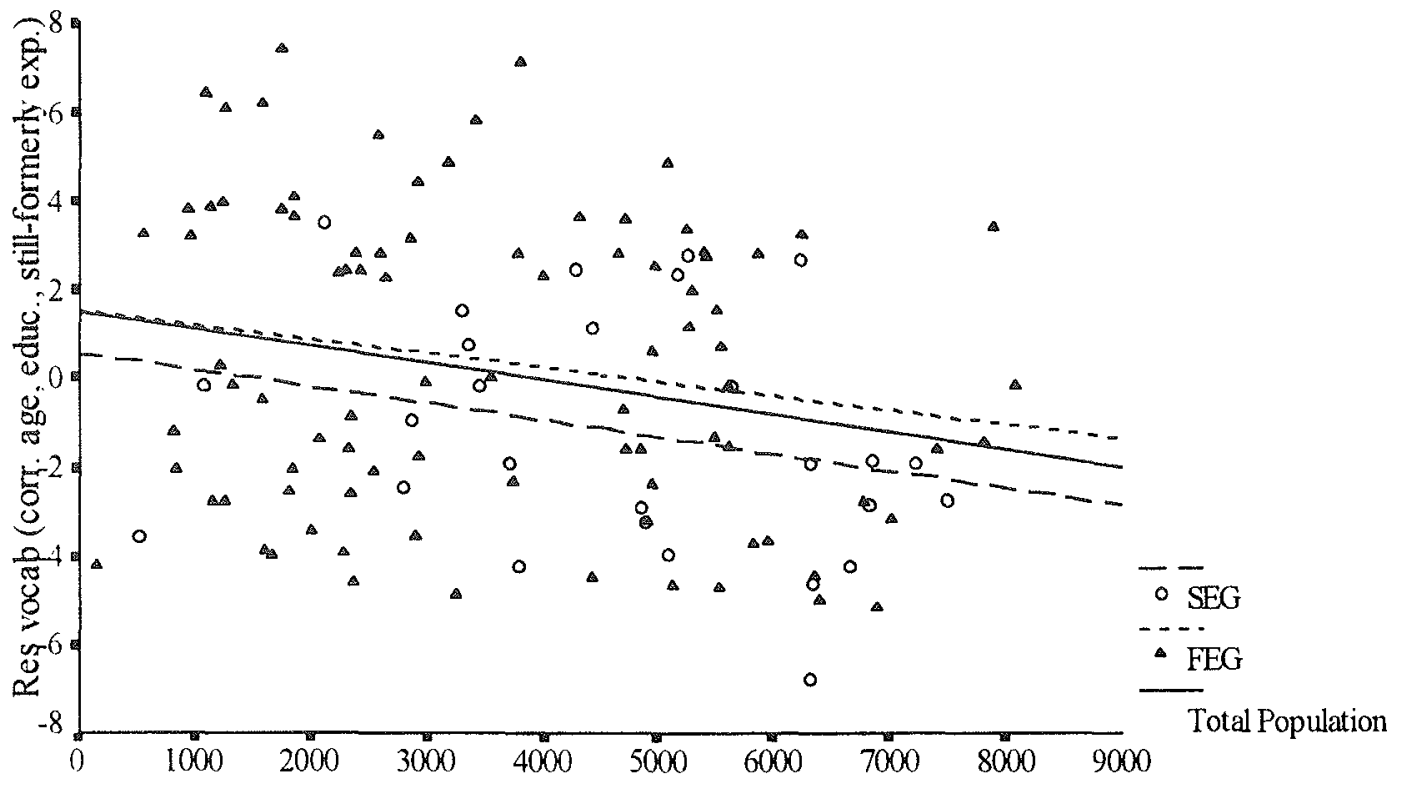

Exposure duration (total hours spend at lamination tasks)

Figure 1. Relationship between the residual vocabulary score (corrected for age and years of education) and the exposure duration (total hours spent at lamination tasks). The result of the linear regression is represented by the full line for the total group $(r=-0.20, P=0.03)$, by the dashed line for the still-exposed group (SEG) $(r=-0.26, P=0.08)$, and by the dotted line for the formerly exposed group (FEG) $(r=-0.19, P=0.07)$.

and years of education. This correction did not change the relationship between the exposure duration and the residual vocabulary score (linear regression, $r=-0.20$, $\mathrm{P}=0.03$ ). The relation between the exposure duration and the vocabulary score was borderline significant in both the still-exposed group and formerly exposed group separately (still-exposed group $\mathrm{r}=-0.26, \mathrm{P}=0.08$; formerly exposed group $r=-0.19, \mathrm{P}=0.07$ ) (figure 1 ).

\section{Discussion}

Some authors have reported that the results of vocabulary tests can be influenced by solvent exposure itself ( 6 , $7,8)$. In another study, the data presented also indicated a slow decrease in the vocabulary score with increasing exposure duration, although this observation was not commented upon by the authors (9). Our data sustain these previous findings. Increasing duration of exposure lowered the vocabulary results significantly (partial $\mathrm{r}=-$ $0.24, \mathrm{P}=0.01$ ). On the average, a total amount of 5000 to 6000 hours of laminating work seems to lower a person's vocabulary score by 2 points (figure 1 ).

Nevertheless, one can argue that the results of our study were influenced by several confounding factors. First, the division of the original group into the still-exposed group and the formerly exposed group could have introduced bias (eg, due to the procedures by which workers were made redundant or because workers with higher language abilities were possibly more capable of getting another job and hence left exposure earlier than others). In addition, the educational level of the nonparticipating persons, who belonged mostly to the formerly exposed group, seemed to be lower than that of the ones who were included.

However, even after correcting the vocabulary score for the difference in the vocabulary results between the formerly exposed group and the still-exposed group, a negative relationship between the duration of exposure to styrene and the residual vocabulary score persisted ( $\mathrm{r}=-$ $0.20, \mathrm{P}=0.03$ ). Moreover, the negative influence of exposure duration was found in both groups separately (figure 1). Therefore, although potential bias in the selection of the formerly exposed group may have influenced the difference in the vocabulary score between the 2 groups, it did not seem to alter the relationship between the duration of styrene exposure and the vocabulary results.

This negative influence of styrene exposure on vocabulary could be the result of a direct toxic effect, or it could be due to the narcotic effect of styrene, with its typical end-of-the-day somnolence. The latter may prevent workers from participating in social, cultural, or intellectual activities so that they do not cultivate their language abilities to the same extent as others.

We conclude that the use of short vocabulary tests as hold tests in cross-sectional studies on solvent-exposed workers may be limited, as the tests seem to lack the essential toxicity-independent property. In this situation, their use as a covariable in the statistical analysis may 
mask the dose-effect relation between exposure and neuroperformance.

\section{References}

1. Gade A, Mortensen EL, Bruhn P. "Chronic painter's syndrome": a reanalysis of psychological test data in a group of diagnosed cases, based on comparison with matched controls. Acta Neurol Scand 1988;77:293-306.

2. Lehrl S, Triebig G, Fisher B. Multiple choice vocabulary test MWT as a valid and short test to estimate premorbid intelligence. Acta Neurol Scand 1995;9:335 - 45.

3. Veulemans H, Daems J, Masschelein R. [Reinforced polyester: air monitoring and biological monitoring.] Cah Arbeidsgeneeskunde 1986;22:75-83.

4. Viaene MK, Masschelein R, Veulemans H. Subclinical neurobehavioural effects of occupational styrene exposure: reversibility: book of abstracts. Stockholm: 25 th International Congress on Occupational Health, 1996: p 338.
5. Letz R. Use of computerized test batteries quantifying neurobehavioral outcomes. Environ Health Perspect 1991;90:195-8.

6. Kishi R, Harabuchi I, Katakura Y, Ikeda T, Miyake H. Neurobehavioral effects of chronic occupational exposure to organic solvents among Japanese industrial painters. Environ Res 1993;62:303-13.

7. Michélsen H, Lundberg I. Neuropsychological verbal tests may lack "hold" properties in occupational studies of neurotoxic effects. Occup Environ Med 1996;53:478—83.

8. Flodin U, Ekberg K, Andersson L. Neuropsychiatric effects of low exposure to styrene. Br J Ind Med 1989;46:805-8.

9. Mutti A, Mazzucchi A, Rustichelli P, Frigeri G, Arfini G, Franchini I. Exposure-effect and exposure-response relationships between occupational exposure to styrene and neuropsychological functions. Am J Ind Med 1984;5:275-86.

Received for publication: 10 June 1997 